\title{
Desigualdades na elite da Ciência Política brasileira
}

\author{
Inequalities in the elite of Brazilian Political Science
}

Desigualdades en la elite de la Ciencia Política brasileña

\author{
Darcia Rangel Candido ${ }^{1}$ \\ (D) João Feres Júnior ${ }^{1}$ \\ (1) Luiz Augusto Campos ${ }^{1}$
}

\begin{abstract}
Resumo: O objetivo deste artigo é examinar um aspecto frequentemente negligenciado nos estudos sobre a Ciência Política no Brasil: as desigualdades internas à comunidade científica. Para tal, começamos por localizar nossa contribuição na literatura especializada. Em seguida, analisamos os perfis de gênero, raça e região geográfica dos docentes de todos os programas de pós-graduação da área reconhecidos pela Coordenação de Aperfeiçoamento de Pessoal de Nível Superior (Capes). Os resultados mostram que a disciplina apresenta assimetrias de gênero e severa desigualdade racial, o que não pode ser totalmente explicado pelas diferenças regionais do país. A fim de observar o dado em perspectiva mais ampla, comparamos as características da Ciência Política às da Sociologia e da Antropologia e concluímos que a primeira é mais desigual em ambas as dimensões.
\end{abstract}

Palavras-chave: Ciência Política. Gênero. Raça. Desigualdades. História.

\begin{abstract}
The aim of this article is to examine an aspect often neglected by the studies about political science in Brazil: inequalities among the scientific community. To do this, we start by first locating our contribution within the literature. Then, we analyze the gender, race and geographic profile of the teachers of all postgraduate programs in the area recognized by the Coordination for the improvement of higher education personnel (Capes). The results show that the discipline presents asymmetries of gender and severe racial inequality, which cannot be fully explained by the regional differences of the country. In order to observe the data in a broader perspective, we compare the characteristics of Political Science with those of Sociology and Anthropology and conclude that the former is more unequal in both dimensions.
\end{abstract}

Keywords: Political Science. Gender. Race. Inequalities. History.

Resumen: El objetivo de este artículo es examinar un aspecto frecuentemente descuidado en los estudios sobre la Ciencia Política en Brasil: las desigualdades entre la comunidad científica. Para ello, empezamos por localizar nuestra contribución en

\footnotetext{
${ }^{1}$ Universidade do Estado do Rio de Janeiro (Uerj, Rio de Janeiro, RJ, Brasil). autores.dados_biográficos
} 
la literatura especializada. A continuación, analizamos los perfiles de género, raza y región geográfica de los docentes de todos los programas de postgrado del área reconocidos por la Coordinación de perfeccionamiento de personal de nivel superior (Capes). Los resultados muestran que la disciplina presenta asimetrías de género y severa desigualdad racial, lo que no puede ser totalmente explicado por las diferencias regionales del país. A fin de observar el dato en perspectiva más amplia, comparamos las características de la Ciencia Política a las de la Sociología y Antropología y concluimos que la primera es más desigual en ambas dimensiones.

Palabras clave: Ciencia Política. Género. Raza. Desigualdades. Historia.

\section{Introdução}

O surgimento de estudos sobre a Ciência Política brasileira, como uma disciplina acadêmica em desenvolvimento, tem registros de pelo menos setenta anos atrás. Em 1950, quando ainda nem possuía instituições especializadas de ensino e pesquisa, o Brasil foi eleito pela Organização das Nações Unidas para a Educação, a Ciência e a Cultura (Unesco) como um dos quatro casos latino-americanos, junto ao México, Argentina e Uruguai, a ser analisado na coletânea Contemporary political science, que buscava estimar a estruturação da área em distintos contextos nacionais. ${ }^{1}$ Redigido por Djacir Menezes, o ensaio septuagenário Political Science in Brazil during the last thirty years é um documento histórico, embora curto e de pouco conteúdo, que atesta o estágio incipiente de demarcação desse campo de conhecimento durante meados do século 20. À época, o cenário brasileiro apresentava indícios de baixa profissionalização, caracterizados pela ausência de cursos de formação e escassez de investigações sistemáticas sobre a política, quase sempre dominadas por perspectivas sociológicas, a cargo de professores universitários de faculdades de direito, ou mesmo de elites intelectuais diletantes (Unesco, 1950).

Ao longo das últimas décadas, transformações intensas ocorreram na organização da disciplina no país. Além da criação e expansão de programas de graduação, mestrado e doutorado, a Ciência Política brasileira passou a desfrutar de um ascendente grau de internacionalização, ampliou e consolidou a atuação de uma associação profissional (a Associação Brasileira de Ciência Política - ABCP - fundada em 1984) e consagrou periódicos que difundem trabalhos concentrados em fenômenos políticos. Os exames acerca da trajetória

\footnotetext{
${ }^{1}$ As primeiras pós-graduações em Ciência Política foram criadas no Brasil em 1969 no Instituto Universitário de Pesquisas do Rio de Janeiro (Iuperj) e na Universidade Federal de Minas Gerais (UFMG).
} 
da área, por sua vez, também mudaram, progredindo em regularidade e diversidade de enfoques. Em contrapartida, nenhuma dessas alterações resultou em mais atenção ao perfil da própria comunidade acadêmica e às desigualdades internas ao exercício da profissão. O objetivo deste artigo é colaborar para atenuar tal falha persistente a partir do mapeamento da composição nacional da elite intelectual de cientistas políticos.

A elite intelectual referida no presente trabalho é definida pelos professores de pós-graduação de grandes áreas das Ciências Sociais (Antropologia, Ciência Política e Sociologia), uma vez que eles praticamente detêm o monopólio sobre os espaços de formação das novas gerações de profissionais, concentram os recursos de pesquisa, editam os principais periódicos que circulam o conhecimento especializado, coordenam os grupos de discussão em congressos e frequentemente são as referências consultadas pela mídia acerca de temas de importância pública.

$\mathrm{O}$ texto está dividido em três partes. Inicialmente, elaboramos um breve balanço bibliográfico sobre a evolução das pesquisas com relação à diversidade na Ciência Política brasileira, demonstrando a sua exiguidade, sobretudo se comparada aos debates internacionais. Em seguida, explicamos a metodologia empregada no estudo e apresentamos dados sobre gênero, raça e região de atuação dos quadros docentes de cursos de mestrado e doutorado em Ciência Política, comparados à Antropologia e à Sociologia. Por fim, fazemos um apanhado crítico das informações e sugerimos hipóteses para investigações futuras.

\section{Estudos sobre a Ciência Política como uma agenda de pesquisa}

As primeiras revistas brasileiras que declaravam entre suas finalidades disseminar estudos sobre a política começaram a surgir alguns anos depois do ensaio de Menezes (1950). ${ }^{2}$ Entre as edições iniciais dessas publicações, um exercício de análise do desenvolvimento da Ciência Política se destaca pelo seu pioneirismo: o artigo de Heloisa Michetti e Maria Teresa Kerbauy, veiculado em 1969 na Revista de Ciência Política, da Fundação Getúlio Vargas. Em A Situação do Ensino e Pesquisa de Ciência Política no Brasil, as autoras exploram os resultados de um survey direcionado a professores brasileiros que se identificavam como cientistas políticos. ${ }^{3}$ Em um período no

\footnotetext{
${ }^{2}$ São exemplos disso a Revista Brasileira de Estudos Politicos, de 1956, a Revista de Direito Público e Ciência Politica, de 1958, a Revista de Ciência Politica, de 1967 e a Dados, de 1966.

${ }^{3} \mathrm{Na}$ época da publicação, Maria Teresa Kerbauy usava o sobrenome Miceli.
} 
qual a área não desfrutava de institucionalização, Michetti e Kerbauy empreenderam um levantamento com ampla seleção de variáveis, que almejava fornecer um panorama sobre os aspectos de formação profissional, ensino e pesquisa, estimulando o avanço da disciplina em diferentes cantos do país. O questionário indagava diversos assuntos e incluía no seu repertório a consideração da distribuição de gênero dos intelectuais (Michetti e Miceli, 1969). ${ }^{4}$

$\mathrm{O}$ pequeno número de respondentes e o caráter não probabilístico da amostra impossibilitaram a obtenção de resultados estatisticamente significativos, mesmo assim o texto de Michetti e Kerbauy documenta um contexto histórico sobre o qual há pouca informação. As autoras lidaram com uma comunidade científica reduzida e heterogênea, bem como com as limitações tecnológicas de um tempo no qual a comunicação com os entrevistados tinha que ser feita pelos correios. Os cientistas políticos brasileiros de hoje, por sua vez, dispõem de melhores recursos institucionais, financeiros e técnicos para investigações empíricas e, além disso, a disciplina vivencia um boom de publicações que refletem sobre a sua estrutura institucional e epistêmica.

A proliferação de trabalhos que utilizam extensos bancos de dados com informações extraídas de repositórios online de artigos ou da Plataforma Lattes é um dos reflexos mais nítidos da modernização estrutural da produção acadêmica. Tais bancos de dados abrem um novo horizonte de pesquisa que possibilita, por meio do uso de ferramentas de big data, a análise sistemática dos conteúdos e das práticas profissionais da Ciência Política. Inclusive foi criado um neologismo, cientometria, para denominar o conjunto de técnicas de mensuração e avaliação da atividade intelectual. Cenário que resulta do desenvolvimento de um sistema de comunicação científica e do protagonismo crescente que os periódicos receberam na atribuição de prestígio aos profissionais e às instituições de ensino superior no Brasil e no mundo (Marenco, 2014; 2015; 2016; Leite e Codato, 2013). ${ }^{5}$

A produção da Ciência Política brasileira não cresceu somente em volume. Paralelamente houve diversificação dos métodos empregados nas investigações. Os textos exegéticos e interpretativos, muitas vezes estruturados

\footnotetext{
${ }^{4}$ A produção do estudo foi motivada pela criação da Associação Brasileira de Ciência Política, mas não a que conhecemos atualmente. É uma experiência pregressa, escassamente mencionada inclusive pelos especialistas na história da disciplina no país e na América Latina. A Associação Brasileira de Ciência Política (ABCP) que está em pleno funcionamento, hoje, foi criada em 1986. Para conhecer mais sobre a instituição ver: www.cienciapolitica.org.br. Acesso em: 4 fev. 2019.

${ }^{5}$ A ascensão dos periódicos e a decorrente perda de prestígio relativo dos livros foi em boa medida estimulada por instituições de fomento, como a Capes, que induziu as Ciências Sociais a adotarem padrões de comunicação das áreas mais duras da ciência, algo que do ponto de vista pragmatista de Thomas Kuhn, elevaria o status de cientificidade da disciplina (Kuhn, 1962).
} 
meramente em revisões bibliográficas, passaram a sofrer concorrência de artigos baseados no emprego de técnicas quantitativas. Alguns periódicos nacionais de Ciência Política chegaram ao ponto de expurgar trabalhos de teoria de seu escopo em prol de abordagens mais hard ao estudo dos fenômenos políticos. $\mathrm{O}$ livro A Ciência Política no Brasil: 1960-2015, lançado em 2016 e organizado pela $\mathrm{ABCP}$, é uma das evidências da centralidade que as estatísticas descritivas e a mensuração de artigos têm recebido nos debates sobre a disciplina, uma vez que vários dos capítulos adotaram tais técnicas (Avritzer et al., 2016).

Todavia, a despeito da proliferação de reflexões sobre a Ciência Política brasileira, o debate do perfil demográfico das comunidades acadêmicas, das diferentes posições de poder e de status no interior da disciplina segue praticamente inexistente. Nos estudos históricos, predominam narrativas sobre a fundação e o desenvolvimento das instituições, o papel dos intelectuais pioneiros ou referências a fatos particularmente relevantes. A ênfase na excepcionalidade dos indivíduos é dominante, ao passo que há pouca reflexão sobre o conjunto geral dos profissionais e, especialmente, acerca das desigualdades que permeiam os espaços de ensino e pesquisa. Só para indicarmos uma evidência, a simples incursão de Michetti e Kerbauy na mensuração de gênero da totalidade de intelectuais envolvidos na disciplina não foi reproduzida posteriormente.

A tentativa mais próxima àquela de Michetti e Kerbauy, de aferir a composição da comunidade de cientistas políticos brasileiros, foi realizada por Cecilia Carpiuc (2016), que buscou mapear e comparar a presença feminina em inúmeros países latino-americanos. Os resultados sobre o Brasil o posicionam como um dos contextos em que existe uma massa crítica de mulheres entre os especialistas em política, mas que perdura a constituir minoria. A conclusão é extraída com base em informações quantitativas sobre as associações profissionais, os quadros de investigadores dos sistemas nacionais de pesquisa, as autorias de publicações de prestígio, as trajetórias de formação e os quadros docentes. No que toca a esses dois últimos aspectos, no entanto, a autora se restringe a avaliar os programas de pós-graduação mais prestigiados, deixando de apreender possíveis distinções na participação de mulheres de acordo com o nível de reconhecimento das instituições. ${ }^{6}$

Além da pesquisa de Carpiuc (2016), os raros estudos disponíveis sobre as desigualdades na comunidade científica brasileira tematizam as relações de

\footnotetext{
${ }^{6}$ Para o Brasil foram analisados os casos da Universidade Candido Mendes, da Universidade de Brasília, da Universidade de São Paulo, da Universidade Estadual de Campinas, da Universidade do estado do Rio de Janeiro, da Universidade Federal de Minas Gerais e o da Universidade Federal do Rio Grande do Sul. Ver os critérios em Carpiuc (2016).
} 
gênero nos meios intelectuais, considerando, inclusive, interações com questões de classe, mas aplicam o método da análise de trajetórias, reconstituindo os processos de socialização de mulheres específicas das Ciências Sociais. Para a Ciência Política, o perfil feminino que foi objeto regular de estudo é o de Paula Beiguelman, a primeira mulher a ocupar a disciplina de Política da Universidade de São Paulo (Spirandelli, 2014; Silva, 2008; 2016). Não existem, contudo, perspectivas sobre a diversidade racial na disciplina, sejam elas quantitativas ou qualitativas.

Em contraposição à baixa produtividade brasileira sobre o assunto, ele tem sido objeto de investigação em outros contextos nacionais. Há décadas a American Political Science Association divulga na PS: Political Science \& Politics resultados de pesquisas sobre recrutamento e retenção de minorias políticas como mulheres (Benedict et al., 1985; Monroe e Chiu, 2010), latinos (Ávalos, 1991; Monforti e Michelson, 2008) e negros (Ards e Woodard, 1992). Embora cada um desses grupos seja alvo de uma discriminação distinta com efeitos particulares, de acordo com essa bibliografia, os mecanismos de exclusão da academia são similares.

Tais contribuições apontam a entrada e, sobretudo, a saída dos programas de doutorado como os gargalos mais substantivos nas trajetórias de minorias. No entanto, a sub-representação de grupos sociais nos departamentos de Ciência Política não pode ser explicada só pela baixa oferta de doutores e doutoras de determinados perfis. Como notam Monroe e Chiu (2010), a presença de mulheres diminui sensivelmente na medida em que se avança nos estratos da carreira universitária, o que deixa patente a existência de filtros excludentes internos à academia estadunidense. Manuel Ávalos (1991) também chama a atenção para mecanismos discriminatórios mais sutis que incidem sobre minorias étnico raciais. Os poucos indivíduos desses grupos que galgam postos de docentes em universidades estadunidenses, tendem a ser alocados em tarefas administrativas de pouco prestígio, paradoxalmente relacionadas ao incentivo e ao apoio dos alunos oriundos de minorias dentro dos campi (Ávalos, 1991, p. 242). Outro fator de exclusão está no insulamento de minorias em temáticas de pesquisa identitárias e com pouca entrada nos periódicos de maior prestígio da Ciência Política (Ávalos, 1991, p. 243). Cabe ressaltar que parte dessa bibliografia não se preocupa apenas em mensurar a sub-representação das minorias e diagnosticar as suas causas, mas também em propor ações afirmativas para solucionar o problema (Benedict et al., 1985).

A ínfima incorporação de mulheres em postos de trabalho mais elevados é uma realidade partilhada na Ciência Política dos países periféricos, como os latino-americanos (Carpiuc, 2016), e os centrais, como os Estados Unidos 
(Monroe e Chiu, 2010). Na Europa, por seu turno, até regiões historicamente conhecidas como referências em igualdade de gênero padecem desse mal. Por exemplo, a cientista política Johanna Kantola (2008) abordou essa situação no departamento de Ciência Política da Universidade de Helsinki, a mais importante da Finlândia. Após verificar que o quadro docente da instituição era dominado por homens, a acadêmica buscou identificar os fatores que dificultavam a permanência das mulheres na profissão. A partir de surveys e entrevistas, Kantola (2008) explicitou que existem discriminações ocultas, limitadoras de trajetórias femininas, que vão desde expectativas díspares sobre o comportamento de mulheres e homens, como regras de vestimenta e normas de conduta, até à divisão sexual do trabalho e à frequente deslegitimação da expertise feminina por parte de estudantes e orientadores.

Outra similitude nas relações de gênero de diferentes comunidades de cientistas políticos ao redor do globo é a pequena proporção de artigos publicados individualmente por mulheres nas revistas mais bem avaliadas da área (Fernandez, 2006; Cardipuc, 2016; Langan Teele e Thelen, 2017). Linda Grant e Kathryn Ward (1991) buscaram encontrar as causas de assimetrias desse tipo na Sociologia e indicaram empecilhos em diversas etapas do processo de publicação: mulheres recebem escassos financiamentos de pesquisa, predominam em instituições com menor probabilidade de angariar fundos, tendem a utilizar metodologias pouco prestigiosas e submetem menos artigos, dando preferência inicial a revistas de baixo reconhecimento; consequentemente, o grupo conquista menor visibilidade na academia, é menos citado e estabelece poucas redes de contato profissionais.

Recentemente, editores de prestigiados periódicos internacionais da Ciência Política testaram a hipótese de que a disparidade de gênero entre os autores de artigos era determinada por discriminações nas avaliações de submissões. Os resultados, entretanto, não a confirmaram. Um dos maiores problemas das assimetrias entre homens e mulheres, no que tange à publicação em revistas, parece continuar sendo a menor proporção de envio de textos de autoria feminina, o que foi constatado em incontáveis casos (Peterson, 2018; Samuels, 2018; König e Ropers, 2018; Tudor e Yashar, 2018). No Brasil, a Dados - Revista de Ciências Sociais evidenciou o entrave em nota editorial recente: $60 \%$ dos artigos submetidos foram assinados por homens, enquanto apenas $40 \%$ por mulheres (Brigel, 2016).

$\mathrm{O}$ artigo ora apresentado pretende contribuir para as reflexões sobre desigualdades na Ciência Política no contexto brasileiro, revelando de modo exploratório as assimetrias de gênero, raça e região geográfica em um posto elitizado da área, a docência dos programas de pós-graduação. Mesmo que 
não seja possível assumir que o conhecimento produzido no interior de uma disciplina acadêmica reflita de modo imediato o perfil social de seus praticantes, é difícil defender que não haja qualquer interação entre essas variáveis. A relação entre inclusão de grupos específicos e consolidação de novas temáticas parece valer, por exemplo, para a questão racial.

A branquitude histórica da Ciência Política brasileira se reflete na ausência quase completa de estudos sobre a questão racial na área. Levantamentos recentes mostram que pioneiros como Wanderley Guilherme dos Santos, Bolívar Lamounier, Amauri de Souza e Glaucio Soares empreenderam pesquisas sobre a interface entre raça e política ainda nas primeiras décadas de institucionalização da disciplina (Campos, 2015; Rodrigues et al., 2017). Contudo, a temática não se consolidou como subárea, ao contrário do que ocorreu, mesmo que lentamente, com os estudos de gênero, o que provavelmente reflete o número exíguo de cientistas políticos pretos e pardos, como veremos a seguir. Antes, porém, apresentamos a metodologia empregada no trabalho. ${ }^{7}$

\section{Metodologia}

A base de dados utilizada neste artigo foi obtida por meio de raspagem da Plataforma Sucupira, que contém os resultados de acompanhamento do Sistema Nacional de Pós-Graduação (SNPG). Mantida pela Coordenação de Aperfeiçoamento de Pessoal de Nível Superior (Capes), a página permite consultar as avaliações de programas de pós-graduação, bem como as informações sobre o corpo docente que integra cada uma dessas instituições. ${ }^{8}$ Com a finalidade de analisar a Ciência Política e estabelecer alguns paralelos com as outras duas grandes áreas das Ciências Sociais, o começo do nosso trabalho foi dividido em duas etapas: primeiro selecionamos todos os cursos de mestrado e doutorado creditados pela Capes nas áreas de (a) Ciência Política e Relações Internacionais, (b) Sociologia e (c) Antropologia. Posteriormente, em outubro de 2017, baixamos as listas de professores permanentes vinculados a eles.

Para determinar a variável raça, empregamos a técnica da heteroclassificação múltipla, bastante utilizada e discutida em estudos de relações raciais quando não se tem acesso direto à autoidentificação dos indivíduos (Muniz, 2012; Silva, 1999; Bastos et al., 2008). O método consiste

\footnotetext{
7 Uma área temática dedicada à questão racial foi aprovada somente no encontro da $\mathrm{ABCP}$ de 2018 e entrará em operação no encontro de 2020.

${ }^{8}$ O fato de a Plataforma Sucupira e a Plataforma Lattes não disponibilizarem dados de raça e gênero dos professores é uma evidência da pouca importância que a Capes dá a esses aspectos na formulação de suas políticas.
} 
na atribuição de pertença racial por meio da análise de fotografias disponíveis na internet. $\mathrm{O}$ procedimento de atribuição é feito em vários estágios para garantir maior grau de intersubjetividade e tem como referência as categorias de cor definidas pelo Instituto Brasileiro de Geografia e Estatística (IBGE) branca, preta, parda, indígena e amarela. Na primeira etapa, três pesquisadores codificam todo o material. Em seguida, separamos os casos consensuais daqueles sobre os quais há dissenso. Passamos então para a recodificação das dúvidas por outros pesquisadores, baseada, se possível, na coleta de mais material fotográfico. Os remanescentes são incorporados ao rótulo outros, no qual são incluídos também os poucos professores dos quais não obtivemos registro de imagem, ou os grupos raciais que não alcançaram percentual significativo. Para facilitar a exposição, adotamos procedimento comum na literatura especializada e apresentamos os dados somando pretos e pardos na categoria não brancos.

Enquanto o método usado para a determinação da variável raça exigiu bastante trabalho humano, a imputação do gênero foi em grande medida computacional, assentada em um pacote de programação que atribui gênero a nomes por meio de um cálculo estatístico. Esse cálculo é construído com referência à lista de frequência de registros de nascimento disponibilizada pelo IBGE no sistema de dados abertos do Governo Federal. ${ }^{9}$ Nomes mais ambíguos ou não identificados pelo algoritmo foram classificados manualmente a partir das fotos e outras informações do docente. Por fim, a região de procedência dos professores, também foi quantificada caso por caso.

\section{Resultados}

A Ciência Política evoluiu tardiamente se comparada à Sociologia e à Antropologia. A criação de pós-graduações começou lenta e a conquista da nota máxima (7) nas avaliações da Capes só aconteceu em 2010 (Marenco, 2014, 2015, 2016; Leite e Codato, 2013).${ }^{10}$ Atualmente, devido em parte à expansão dos programas de Políticas Públicas e de Estudos Estratégicos, a disciplina chegou a ultrapassar a área de Antropologia em número de cursos de mestrado e doutorado em exercício, embora ainda fique atrás da Sociologia. ${ }^{11}$

\footnotetext{
${ }_{9}$ Agradecemos ao técnico em computação André Félix pelo desenvolvimento do pacote de programação e a produção dos dados sobre gênero.

${ }^{10} \mathrm{~A}$ Capes é a principal instituição responsável pela expansão da pós-graduação no Brasil, atuando na acreditação de novos cursos e na avaliação de qualidade de programas de mestrado e doutorado.

${ }^{11} \mathrm{O}$ dado se refere às instituições de mestrado e/ou doutorado. Disponível em: sucupira.capes. gov.br/sucupira/public/consultas/coleta/programa/quantitativos/quantitativoAreaAvaliacao. xhtml. Acesso em: 4 fev. 2019.
} 
Pouco se sabe, porém, sobre o perfil de gênero, raça e região de origem de seus membros.

O Gráfico 1 explicita que a Ciência Política é a área com presença masculina mais elevada entre os docentes (67\%), enquanto a Sociologia é mais equilibrada (53\%) e a Antropologia tem leve predominância de mulheres (52\%). O padrão mais feminizado das áreas correlatas à Ciência Política é mais uma característica que pode ser ressaltada como partilhada entre distintos contextos nacionais, dos países latino-americanos aos norte-americanos e europeus (Carpiuc, 2016).

Gráfico 1 - Gênero dos docentes dos programas de pós-graduação nas grandes áreas de Ciências Sociais

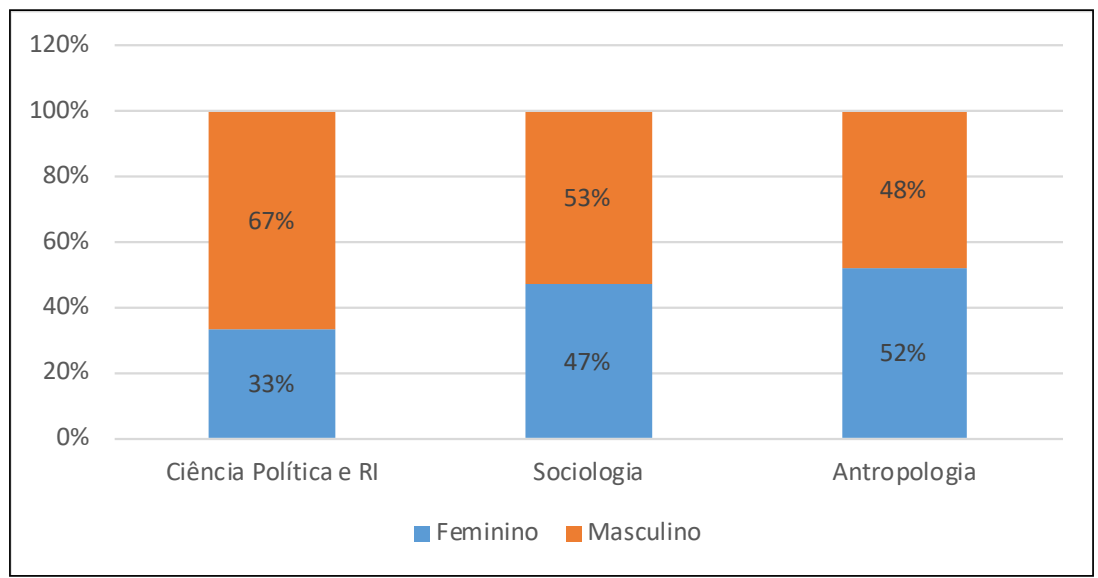

Fonte: Elaborado pelos autores com base em dados da Plataforma Sucupira.

A intensa predominância masculina praticamente não se altera nem quando as instituições de mestrado e doutorado de Ciência Política e Relações Internacionais são vistas separadamente. As exceções ficam a cargo do programa de Políticas Públicas da Universidade Federal do Rio Grande do Sul (Ufrgs), bem como das pós-graduações de Relações Internacionais da Universidade de Brasília (UnB) e da Universidade Federal de Santa Catarina (Ufsc), exemplos em que o total de professoras mulheres fica entre $54 \%$ e $58 \%$. Não obstante, 25 instituições têm população masculina de docentes igual ou superior a $60 \%$, com dois departamentos exclusivamente compostos por homens: o mestrado de Estudos Estratégicos da Universidade Federal Fluminense (UFF) e o mestrado e doutorado em Ciência Política da Universidade Federal do Paraná (UFPR). 
Ainda que as assimetrias entre homens e mulheres nas posições de ensino das pós-graduações sejam significativas, trabalhos que ponderam a relação do poder público com a evolução institucional da Ciência Política não costumam problematizar os impactos das questões de gênero. ${ }^{12}$ Ao quantificar a produção de docentes em revistas de qualidade como um dos fatores para aferir nota aos programas de doutorado e mestrado, a Capes, por exemplo, não desconta o período em que as mulheres ficam em licença maternidade. Recentemente, o projeto Parent in Science mostrou que a taxa de publicações de mulheres é afetada pelo cuidado com os filhos recém-nascidos. O estudo concluiu que $81 \%$ das entrevistadas percebia consequências negativas da gravidez na produtividade mensurada pelas agências de fomento e na concessão de recursos para trabalhos futuros (Andrade, 2018). Ter filhos, portanto, pode representar um atraso na progressão de carreira para mulheres, não só pela desigual divisão do trabalho doméstico e de cuidados, como também pelo descuido dos órgãos públicos em considerar as diferenças de socialização por gênero. ${ }^{13}$

Além disso, os centros de ensino e pesquisa que competem por recursos podem se tornar ambientes hostis para as gerações que se aproximam de temporadas em licença maternidade ou que se enquadram nessas expectativas de gênero. Como os financiamentos para as universidades dependem de resultados quantificáveis, a possibilidade de perda momentânea de força de trabalho acaba parecendo um prejuízo à coletividade. Ademais, a faixa etária do grupo feminino durante o período de formação em graduação e pósgraduação é justamente a da época de maior fertilidade, o que eventualmente cria barreiras para a inserção profissional de mulheres, visto que os concursos para cargos docentes frequentemente reproduzem exigências de produtividade determinadas pelas agências de fomento.

Para adentrar e se manter nos quadros profissionais de instituições acadêmicas, as mulheres que escolhem a maternidade fatalmente precisam trabalhar redobrado, superar discriminações ou contar com o bom senso dos pares. Efeitos peculiares dessas questões, ao grupo de cientistas políticas, ainda precisam ser objeto de maior aprofundamento. O ponto principal é que a Capes simplesmente desconsidera a equidade de gênero como um item de

\footnotetext{
${ }^{12}$ Ver, por exemplo, o estudo de Marenco (2015) sobre o papel criação do sistema de avaliação da Capes na expansão das pós-graduações.

${ }^{13}$ Existem algumas ocorrências que representam exceções recentes como a aprovação, em 2018, da Lei no 13.536, de autoria da deputada do PCdoB da Bahia Alice Portugal. A legislação dispõe sobre melhores garantias de licença maternidade para pesquisadoras de pós-graduação. Disponível em: http://www.planalto.gov.br/ccivil_03/_ato2015-2018/2017/Lei/L13536.htm. Acesso em: 4 de jan. 2019.
} 
avaliação da pós-graduação. O que não fornece nenhum incentivo para que a inserção de mulheres seja tratada como uma prioridade.

Apesar desses fatores adversos, é importante ressaltar que não há correlação entre a proporção de docentes mulheres nos programas de pósgraduação em Ciência Política e Relações Internacionais e a avaliação que eles recebem. Dentre todos os casos que analisamos para a disciplina, sinalizam isso, por exemplo, a presença de professoras nos cursos de mestrado e doutorado de excelência (nota máxima na Capes), que pode ser uma das mais baixas do Brasil, como na Universidade de São Paulo (apenas 23\%), ou uma das mais altas, como na Universidade Federal de Minas Gerais, que tem 47\% de docentes mulheres.

Mais severa que a desigualdade de gênero, todavia, é a desigualdade racial, como revela o Gráfico 2, que contém a distribuição de docentes em programas de pós-graduação de acordo com o grupo de cor ao qual pertencem. Nas três grandes áreas das Ciências Sociais a dominância de brancos é da ordem de quatro para um, com a Ciência Política e a Antropologia praticamente empatadas e a Sociologia levemente menos desigual.

Gráfico 2 - Raça dos docentes dos programas de pós-graduação nas grandes áreas de Ciências Sociais

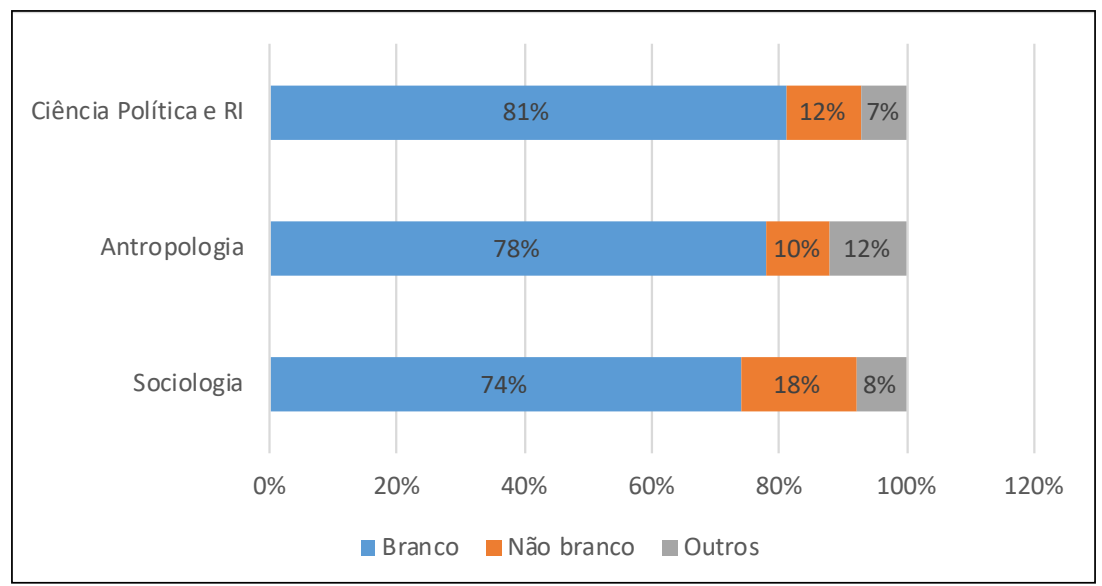

Fonte: Elaborado pelos autores com base em dados da Plataforma Sucupira.

As assimetrias de raça e gênero se prestam quase que perfeitamente à comparação no Brasil, pois ambas dividem a sociedade ao meio: $51,6 \%$ de mulheres para $48,4 \%$ de homens, e $54,9 \%$ de não brancos (pretos e pardos) para 
$44,2 \%$ de brancos. ${ }^{14} \mathrm{Ou}$ seja, as três áreas das Ciências Sociais revelam alto grau de desigualdade racial, pois em seus quadros docentes de pós-graduação os brancos alcançam quase o dobro de sua proporção demográfica. No outro extremo, não brancos são severamente sub-representados, com menos de um quarto de sua proporção demográfica na Ciência Política e menos de um sexto na Antropologia.

Quatro programas de pós-graduação da área de Ciência Política e Relações Internacionais são integrados apenas por professores brancos: Políticas Públicas da Universidade Federal do ABC, Políticas Públicas da Universidade Federal do Rio Grande do Sul (Ufrgs), Ciência Política da Universidade Federal de São Carlos (Ufscar) e Ciência Política da Universidade Estadual de Campinas (Unicamp). Além disso, diferentemente da distribuição de gênero, na qual havia ao menos três programas de instituições com maior presença feminina - na Ufrgs, na UnB e na Ufsc -, em nenhum dos casos analisados a participação de não brancos é minimamente equilibrada.

A desigualdade racial na pós-graduação em Ciência Política certamente é impactada pela alta assimetria da distribuição dos programas e professores pelas diferentes regiões do país. Mas as diferenças geográficas estão longe de explicar a participação desproporcional dos grupos raciais, como ajuda a ilustrar o Gráfico 3.

Gráfico 3 - Distribuição de raça dos docentes de pós-graduação em Ciência Política e Relações Internacionais por região

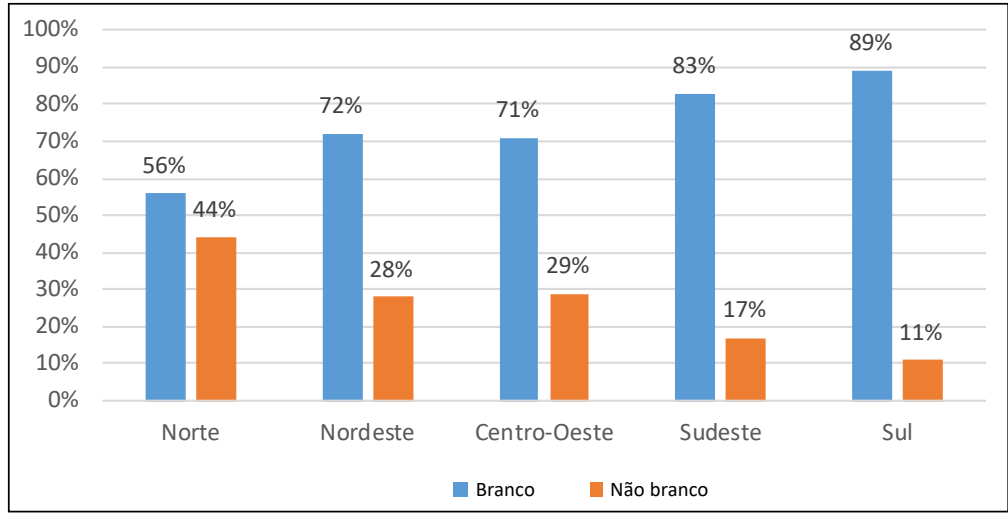

Fonte: Elaborado pelos autores com base em dados da Plataforma Sucupira.

\footnotetext{
${ }^{14}$ Para dados de gênero, ver: https://educa.ibge.gov.br/jovens/conheca-o-brasil/populacao/18320quantidade-de-homens-e-mulheres.html. Para dados de raça, ver: https://agenciadenoticias. ibge.gov.br/agencia-noticias/2012-agencia-de-noticias/noticias/18282-populacao-chega-a205-5-milhoes-com-menos-brancos-e-mais-pardos-e-pretos.
} 
Os autodeclarados brancos no Sudeste somam $55,2 \%$ da população da região, mas na pós-graduação de Ciência Política, esse contingente corresponde a $83 \%$ dos docentes credenciados. Há, portanto, uma discrepância substantiva, de quase trinta pontos percentuais na representatividade dos brancos na disciplina quando comparada à realidade. Na região Sul, os brancos perfazem $78,5 \%$ da população, mas $89,2 \%$ dos professores de mestrado e doutorado da área. A maior disparidade, por fim, está no Nordeste. Nessa região, pretos e pardos somam quase $69 \%$ da população e apenas $27,6 \%$ dos que lecionam na pós-graduação. Em suma, a desigualdade racial varia de região para região, mas em todos os casos ela é pronunciada.

\section{Considerações finais}

O objetivo deste trabalho foi contribuir às análises sobre o desenvolvimento da Ciência Política brasileira a partir da observação de aspectos demográficos da comunidade acadêmica frequentemente subestimados: os perfis de gênero, raça e região geográfica dos docentes. Para tal, classificamos os professores dos programas de pós-graduação nacionais e analisamos características institucionais. Constatamos uma substantiva desigualdade de gênero na disciplina, seja ela medida em relação às proporções de homens e mulheres na população geral do país, que tem ligeira superioridade numérica feminina, ou em relação às áreas de Sociologia e Antropologia, bastante equilibradas nesse quesito. Na Ciência Política existem praticamente dois homens para cada mulher em atividade docente.

A desigualdade racial, contudo, é bem mais contundente. No Brasil, a média verificada é de aproximadamente quatro professores brancos para um não branco lecionando nos cursos de mestrado e doutorado em Ciência Política, padrão que se manifesta de modo similar nas outras duas grandes áreas das Ciências Sociais. Os brancos constituem maioria em quase todos os programas de pós-graduação, independentemente da localização das instituições. A assimetria racial nos quadros docentes de regiões mais desenvolvidas economicamente e mais brancas, como o Sudeste e o Sul, que reúnem a maioria dos centros de ensino e pesquisa, é mais alarmante que a das demais regiões, em números absolutos. Por outro lado, é possível sugerir que a presença superior de não brancos na população do Nordeste, Norte e Centro-Oeste praticamente cancela a relativa maior proporção desse grupo entre os docentes dessas regiões. Em suma, a desigualdade racial é intensa em todo país.

Ainda que o presente trabalho tenha sido um primeiro esforço para mapear e discutir as assimetrias na Ciência Política brasileira, dados estatísticos 
externos permitem formular algumas hipóteses para orientar pesquisas futuras que explorem as causas do contexto de desigualdades. Em 2018, mulheres eram maioria entre os graduandos de Instituições de Ensino Federais (Ifes), $54,6 \%$, e não brancos também, 51,2\% (Gomes et al., 2019). Por que será que o nível de inclusão desses grupos entre os professores de pós-graduação é diferente? A primeira hipótese explicativa é que a inserção de mulheres brancas, quando comparada à da população não branca, no Ensino Superior é mais antiga e extensa, o que favorece o incremento da presença feminina entre a elite acadêmica dos cursos de mestrado e doutorado. Os não brancos, por sua vez, ganharam maior acesso à formação universitária com o advento das cotas raciais, que nas Ifes foram implementadas somente a partir de 2005 (Machado, Eurístenes e Feres Júnior, 2017).

A segunda hipótese para aprofundar a diferença proporcional dos grupos sub-representados, que não cancela a primeira, é a de que não brancos sofrem formas de discriminação mais renitentes que mulheres brancas ao longo da carreira acadêmica. Certamente a maior presença de não brancos na graduação e na pós-graduação, que também têm incorporado cotas raciais, por mais tempo, vai nos permitir testar parcialmente essa pressuposição em breve, isto é, se vislumbramos apenas uma tendência de natureza demográfica ou se há mecanismos ativos de segregação na educação superior explicados por racismo.

É preciso, ademais, explorar os determinantes que tornam a Ciência Política a mais masculina das grandes áreas das Ciências Sociais. Trabalhos como o de Kantola (2008), referidos em seção anterior do texto, também são importantes agendas de pesquisa para as próximas avaliações sobre a disciplina no Brasil. De qualquer forma, é imprescindível atentar para as múltiplas consequências dessas desigualdades, desde a mais básica injustiça social até problemas epistêmicos, como a desvalorização dos estudos de gênero e raça do temário de subáreas de pesquisas na Ciência Política. O primeiro passo para começarmos a sanar essas assimetrias é tomá-las seriamente como objeto de investigação, tal como procuramos fazer na presente contribuição.

\section{Referências}

ANDRADE, Rodrigo de Oliveira. Maternidade no currículo: projeto de pesquisadoras estima impacto das atividades como mãe na carreira científica. Pesquisa Fapesp, São Paulo, ed. 269, 2018. Disponível em: https://revistapesquisa.fapesp.br/2018/07/19/ maternidade-no-curriculo/. Acesso em: 16 out. 2019.

ARDS, Sheila; WOODARD, Maurice C. African Americans in the political science profession. PS: Political Science \& Politics, Washington, v. 25, n. 2, p. 252-259, 1992. Disponível em: https://doi.org/10.2307/419719. Acesso em: 16 out. 2019. 
ÁVALOS, Manuel. The status of Latinos in the profession: problems in recruitment and Retention. PS: Political Science \& Politics, Washington, v. 24, n. 2, p. 241-246, 1991. Disponível em: https://doi.org/10.2307/419943. Acesso em: 16 out. 2019.

AVRITZER, Leonardo; MILANI, Carlos; BRAGA, Maria do Socorro (org.). A ciência politica no Brasil: 1960-2015. Rio de Janeiro: FGV, 2016.

BASTOS, João Luiz et al. Diferenças socioeconômicas entre autoclassificação e heteroclassificação de cor/raça. Revista de Saúde Pública, São Paulo, v. 42, n. 2, p.324-334, 2008. Disponível em: http://dx.doi.org/10.1590/S0034-89102008005 000005. Acesso em: 16 out. 2019.

BENEDICT, Robert C.; NELSON, Dalmas H.; SCHWARTZ-SHEA, Peregrine. The challenge of recruiting women and minority faculty members in political science: a case study in methods. PS: Political Science \& Politics, Washington, v. 18, n. 4, p. 789-793, 1985. Disponível em: https://doi.org/10.1017/S1049096500022721. Acesso em: 16 out. 2019.

BRINGEL, Breno. Nota editorial: política e fluxo editorial da Dados. Dados, Rio de Janeiro, v. 59, n. 2, p.311-321, 2016. Disponível em: http://dx.doi.org/ 10.1590/00115258201678. Acesso em: 16 out. 2019.

CAMPOS, Luiz Augusto. Socialismo moreno, conservadorismo pálido? Cor e recrutamento partidário em São Paulo e Rio de Janeiro nas eleições de 2012. Dados, Rio de Janeiro, v. 58, n. 3, p.689-719, 2015. Disponível em: http://dx.doi. org/10.1590/00115258201556. Acesso em: 16 out. 2019.

CARPIUC, Cecília Rocha. Women and diversity in Latin American Political Science. European Political Science, [s. l.], v. 15, n. 4, p. 457-475, 2016. Disponível em: https:// doi.org/10.1057/s41304-016-0077-4. Acesso em: 16 out. 2019.

FERNÁNDEZ, María de los Ángeles. Mujer y ciencia política en Chile ¿Algo nuevo bajo el sol? Politica: Revista de Ciência Política, Santiago, v. 46, p. 261-289, 2006. Disponível em: https://doi.org/10.5354/0716-1077.2006.17015. Acesso em: 16 out. 2019.

GRANT, Linda; WARD, Kathryn B. Gender and publishing in sociology. Gender and Society, Newbury Park, v. 5, n. 2, p. 207-223, 1991. Disponível em: https://www.jstor. org/stable/189485. Acesso em: 16 out. 2019.

GOMES, Darcilene et al. V Pesquisa do perfil socioeconômico e cultural dos estudantes de graduandos das Instituições Federais de Ensino Superior Brasileiras. Uberlândia: [s. n.], 2019.

KANTOLA, Johanna. Why do all the women disappear? Gendering processes in a Political Science department. Gender, Work and Organization, Oxford, v. 15, n. 2, p. 202-225, 2008. Disponível em: https://doi.org/10.1111/j.1468-0432.2007.00376.x. Acesso em: 16 out. 2019. 
KÖNIG, Thomas; ROPERS, Guido. Gender and editorial outcomes at the American Political Science Review. PS: Political Science \& Politics, Washington, v. 51, n. 4, p. 849-853, 2018. Disponível em: https://doi.org/10.1017/S1049096518000604. Acesso em: 16 out. 2019.

KUHN, Thomas. The structure of scientific revolutions. Chicago: University of Chicago Press, 1962.

LANGAN TEELE, Dawn; THELEN, Kathleen. Gender in the journals: publication patterns in political science. PS: Political Science \& Politics, Washington, v. 50, n. 2, p.443-447, 2017. Disponível em: https://doi.org/10.1017/S1049096516002985. Acesso em: 16 out. 2019.

LEITE, Fernando; CODATO, Adriano. Autonomização e institucionalização da Ciência Política brasileira: o papel do sistema Qualis-Capes. Agenda Política, São Paulo, v. 1, n. 1, p. 1-21, 2013. Disponível em: http://www.agendapolitica.ufscar.br/ index.php/agendapolitica/article/view/10/8. Acesso em: 16 out. 2019.

MACHADO, Marcell; EURÍSTENES, Poema; FERES JÚNIOR, João. Políticas de ação afirmativa nas universidades estaduais: levantamento das políticas de ação afirmativa GEMAA. Rio de Janeiro: Iesp-Uerj, 2017. Disponível em: http://gemaa. iesp.uerj.br/wp-content/uploads/2018/10/Lev-Estaduais-2017.pdf. Acesso em: 16 out. 2019.

MARENCO, André. Cinco décadas de Ciência Política no Brasil: institucionalização e pluralismo. In: AVRITZER, Leonardo; MILANI, Carlos; BRAGA, Maria do Socorro (org.). A ciência política no Brasil: 1960-2015. Rio de Janeiro: FGV, 2016. p. 141-163.

MARENCO, André. The three Achilles' heels of Brazilian political science. Brazilian Political Science Review, São Paulo, v. 8, n. 3, p.3-38, 2014. Disponível em: http:// dx.doi.org/10.1590/1981-38212014000100019. Acesso em: 16 out. 2019.

MARENCO, André. When institutions matter: Capes and political science in Brazil. Revista de Ciência Política, São Paulo, v. 35, n. 1, p.33-46, 2015. Disponível em: http://hdl.handle.net/10183/141336. Acesso em: 16 out. 2019.

MENEZES, Djacir. Political science in Brazil during the last thirty years. In: UNESCO (org.). Contemporary political science: a survey of methods, research and teaching. Paris: Unesco, 1950. p. 228-232.

MICHETTI, Heloísa Helena; MICELI, Maria Teresa. A situação do ensino e pesquisa de ciência política no Brasil. Revista de Ciência Política, [s. l.], v. 2, n. 4, p.89-110, 1969.

MONFORTI, Jessica Lavariega; MICHELSON, Melissa R. Diagnosing the leaky pipeline: continuing barriers to the retention of Latinas and Latinos in political science. PS: Political Science \& Politics, Washington, v. 41, n. 1, p. 161-166, 2008. Disponível em: https://doi.org/10.1017/S1049096508080232. Acesso em: 16 out. 2019. 
MONROE, Kristen Renwick; CHIU, William F. Gender equality in the academy: the pipeline problem. PS: Political Science \& Politics, Washington, v. 43, n. 2, p.303-308, 2010. Disponível em: https://doi.org/10.1017/S104909651000017X. Acesso em: 16 out. 2019.

MUNIZ, Jerônimo O. Preto no branco? Mensuração, relevância e concordância classificatória no país da incerteza racial. Dados, Rio de Janeiro, v. 55, n. 1, p. 251-282, 2012. Disponível em: http://dx.doi.org/10.1590/S0011-525820120001 00007. Acesso em: 16 out. 2019.

PETERSON, David A. M. Author gender and editorial outcomes at political behavior. PS: Political Science \& Politics, Washington, v. 51, n. 4, p. 866-869, 2018. Disponível em: https://doi.org/10.1017/S104909651800063X. Acesso em: 16 out. 2019.

PINHEIRO, Dimitri. Jogo de damas: trajetórias de mulheres nas ciências sociais paulistas (1934-1969). Cadernos Pagu, Campinas, n. 46, p. 165-196, 2016. Disponível em: http://dx.doi.org/10.1590/18094449201600460165. Acesso em: 16 out. 2019.

RODRIGUES, Cristiano; MONAGREDA, Johanna; PORTO, Nathália. Estudos sobre raça, racismo e etnicidade na Ciência Política brasileira: uma análise do campo a partir de seu estado da arte. In: Encontro Anual da Anpocs, 41, 2017, Caxambu. Anais [...]. Caxambu: Anpoc, 2017.

SAMUELS, David. Gender and editorial outcomes at comparative political studies. PS: Political Science \& Politics, Washington, v. 51, n. 4, p. 854-858, 2018. Disponível em: https://doi.org/10.1017/S1049096518000616. Acesso em: 16 out. 2019.

SILVA, Dimitri Pinheiro. Da política à ciência política, da ciência política à política: a trajetória acadêmica de Paula Beiguelman (1949-1969). 2008. Dissertação (Mestrado em Sociologia) - Programação de Pós-Graduação em Sociologia, Departamento de Sociologia, Faculdade de Filosofia, Letras e Ciências Humanas, Universidade de São Paulo, São Paulo, 2008.

SILVA, Nelson do Valle. Morenidade: modos de usar. In: HASENBALG, Carlos; SILVA, Nelson do Valle; LIMA, Márcia (org.). Cor e estratificação social. Rio de Janeiro: Contra Capa, 1999. p. 86-106.

SPIRANDELLI, Claudinei Carlos. Professoras, cátedras e o ensino de sociologia na USP: anos 1940-1960. Revista Brasileira de Sociologia, São Cristóvão, v. 2, n. 3 , p. 151-180, 2014. Disponível em: http://dx.doi.org/10.20336/rbs.67. Acesso em: 16 out. 2019.

TUDOR, Carissa; YASHAR, Deborah. Gender and the editorial process: world politics, 2007-2017. PS: Political Science \& Politics, Washington, v. 51, n. 4, p.870-880, 2018. Disponível em: https://doi.org/10.1017/S1049096518000641. Acesso em: 16 out. 2019. 
UNESCO. Contemporary political science: a survey of methods, research and teaching. Paris: Unesco, 1950.

Recebido em: 3/2/2019.

Aprovado em: 25/6/2019.

Publicado em: 15/12/2019.

Autora correspondente:

Marcia Rangel Candido

Instituto de Estudos Sociais e Políticos (Iesp-Uerj)

Rua da Matriz, 82

22260-100, Botafogo, RJ, Brasil

MARCIA RANGEL CANDIDO <marciarangelcandido@gmail.com>

Doutoranda em Ciência Política no Instituto de Estudos Sociais e Políticos da Universidade do Estado do Rio de Janeiro (Uerj, Rio de Janeiro, RJ, Brasil). O presente trabalho foi realizado com apoio da Coordenação de Aperfeiçoamento de Pessoal de Nível Superior-Brasil (Capes) - Código de Financiamento 001.

Orcid: http://orcid.org/0000-0003-3466-000X

JOÃO FERES JÚNIOR <jferes@iesp.uerj.br>

Doutor em Ciência Política pela City University of New York (Nova Iorque, USA). Diretor do Instituto de Estudos Sociais e Políticos da Universidade do Estado do Rio de Janeiro (Uerj, Rio de Janeiro, RJ, Brasil). Bolsista produtividade do CNPq, bolsista Cientista do Nosso Estado da Faperj, membro do INCT Instituto da Democracia e da Democratização da Comunicação

Orcid: http://orcid.org/0000-0002-5830-0458

Luiz Augusto Campos <lascampos@gmail.com>

Doutor em Sociologia pelo Instituto de Estudos Sociais e Políticos da Universidade do Estado do Rio de Janeiro (Uerj, Rio de Janeiro, RJ, Brasil). Professor nos Programas de Pós-Graduação em Sociologia e em Ciência Política do Instituto de Estudos Sociais e Políticos da Universidade do Estado do Rio de Janeiro (Uerj, Rio de Janeiro, RJ, Brasil). Bolsista produtividade do CNPq, bolsista Jovem Cientista do Nosso Estado da Faperj e bolsista Procientista da Uerj.

Orcid: http://orcid.org/0000-0003-2153-547X 